\title{
A Statistical Downscaling Technique for Assessment of Meteorological Parameters under Climate Change Condition Using SDSM-DC Model in Raipur District
}

\author{
Dularchand Chaudhary ${ }^{1}$, Dinesh Kumar' ${ }^{*}$, R. K. Jaiswal ${ }^{2}$ and A. K. Nema ${ }^{1}$
}

${ }^{1}$ Dept. of Farm Engineering, Institute of Agricultural Sciences, Banaras Hindu University, Varanasi, Uttar Pradesh (221 005), India

${ }^{2}$ National Institute of Hydrology, Ganga Plains South Regional Centre, WALMI CAMPUS, Bhopal, Madhya Pradesh (462 016), India

\section{Corresponding Author}

Dinesh Kumar

e-mail: dineshcae10@gmail.com

\author{
Article History \\ Article ID: 3 C0268 \\ Received in $27^{\text {th }}$ September, 2017 \\ Received in revised form $05^{\text {th }}$ August, 2018 \\ Accepted in final form $16^{\text {th }}$ August, 2018
}

\begin{abstract}
Changes in maximum and minimum temperature with occurrence of extreme events are major threat to future food security due to climate change. Climate change related occurrence of extreme events can have serious consequences for human health and agricultural production. Chhattisgarh (Raipur) is already facing increased temperatures in summers. In the present study, efforts have been made to analyze meteorological parameters aspects of climate change at Raipur district in Chhattisgarh. The data of climatic parameters including maximum temperature, minimum temperature, relative humidity, sunshine hour, wind speed and evaporation has been used for forecasting the three future periods FP-1 (2011-2040), FP-2 (2041-2070) and FP-3 (2071-2099) under A1B and A2 climate forcing conditions. The statistical downscaling technique proposed in SDSM-DC 5.2 was used to select an appropriate set of climate predictors. The selected sets of predictors were further used to project future climate for three different periods and multiple series after debiased were further used to ascertain the change from base period mean monthly values for climatic parameters and peak over threshold \& peak below threshold values. Generation of multiple series for meteorological parameters under A1B and A2 climate scenario has been worked for analysis of changes in meteorological parameters due to change of climate. A comparison of different meteorological parameters has been revolved that helped for making future planning under climate change condition.
\end{abstract}

Keywords: Climate change, meteorological parameters, Raipur, statistical downscaling, SDSM-DC

\section{Introduction}

Various reports of Intergovernmental panel on climate change (IPCC) confirmed that the global temperature is rising due to increasing concentration of greenhouse gases causing negative effects on water resources, environment, health, agriculture, ecology etc. Increase in land and ocean surface temperature, spatial and temporal change in rainfall, sea levels rise, increase in frequency and increased intensity of extreme events are very likely due to human intervention and other natural forces (IPCC, 2002). The latest report of IPCC included another aspect of change in precipitation regime and expected more sever wet extreme in many areas where mean precipitation projected may decreased, resulting more flooding in Asian monsoon and other tropical region (IPCC, 2007).

General Circulation Models (GCMs) are an important tool for assessing the impact of climate change on a range of human and natural systems. Climate models, particularly the GCMs, currently provide the most important source of information for constructing scenarios of climate change, which provide climate information at a higher spatial resolution, gradually becoming available. GCMs are based on physical laws and physical-based empirical relationships and are mathematical representations of the atmosphere, ocean and cryo-sphere and land surface processes. In order to determine how climate change may occur in the future, it is essential to understand how the concentrations of atmospheric components which affect the Earth's energy balance may change. The IPCC fourth assessment report, namely the Special Report on Emissions Scenarios (SRES) features four storylines which are labeled as A1, A2, B1 and B2, chronicles of qualitative (e.g., political, social, economical, cultural, environmental and educational developments) emissions drivers (IPCC, 2007). These storylines depict the relationship between the forces driving greenhouse gases and aerosol emissions and their development during the $21^{\text {st }}$ century. For predicting the possible future climate, these SRES emissions scenarios are considered useful. Among these are four scenarios, A1, B1, A2 and B2 scenarios were used in this study. The A2 storyline portrays a very diverse world. This storyline depicts that there is a continuous increase in population, economic developments on regional levels, 
economic growth and technological changes are more uneven and slower in comparison to other three storylines. In B2 storyline, there is a continuous increase in global population, but at a slower rate than A2 scenario. The B2 scenario is also directed towards environmental protection and social equity; it focuses on both local and regional levels (IPCC, 2007). General Circulation Models or global climate models (GCMs) are among the best available tools to represent the main features of the global distribution of basic climate parameters at continental and large regional scales. But these models are unable to produce the details of regional climate conditions at different temporal and spatial scales. The anthropogenic global climate change would lead to changes in large-scale atmospheric features. The current generation of General Circulation Models (GCMs) operates on a coarser scale. However, the climate impact studies in hydrology often require climate change information at finer spatial scale. Hence, there is a great need to use downscaling techniques for downscaling GCM predictions of climate change to regional and local or station scales. Downscaling techniques have been designed to link the gap between the information that the climate modeling community can currently provide and that required by the hydrologists for assessing the possible impact of climate change on water resources (Maraun et al., 2010). There are two broad categories of downscaling procedures: (a) dynamical downscaling techniques, which involves the extraction of regional scale information from large-scale GCM data based on the modeling of regional climate dynamical processes, and (b) statistical downscaling techniques that rely on the empirical relationships between predictors (large-scale atmospheric variables) and predictands (surface environment variables) (Ghosh and Mishra, 2010). There are many advantages and disadvantages of dynamical downscaling and statistical downscaling techniques for climate change impacts, which indicate that neither technique is better than the other (Wilby et al., 2000). Based on the assessment of the climate change impacts on the hydrologic regimes of a number of selected basins, it was found that these two techniques could reproduce some general features of the basin climatology, but both displayed systematic biases with respect to observations as well. Further, it was found that the assessment results were dependent on the specific climatology of the basin under consideration. Several statistical downscaling techniques (transfer functions, weather typing approach, SDSM) have been developed to establish relationships between meteorological variables and the large-scale GCMs outputs.

The Statistical Downscaling Model-Decision Centric (SDSMDC) is user friendly software for development of future climate data sets by statistical downscaling of GCMs data and can be used as decision support system (DSS) to generate plausible daily weather series under manually guided trend conditions and other exotic variables such as tidal surge. The SDSM-DC is a transfer function based model can be categorized as a hybrid of stochastic, weather generator and regression model uses multiple linear regressions between daily predict and a set of predictors to represent local weather through seven major steps including quality control \& data transformation, screening of predictor variables, model calibration, weather generation, statistical analysis, graphical representation and scenario generation (Fowler et al., 2007). This software can also be used for in-filling missing data in data sparse region to understand regional climate system (Wilby et al., 2014). The detail about the application, strength and weakness of SDSM can be found in Wilby \& Dettinger, 2000, Wilby et al., 2002, Wilby et al., 2004 etc. The climatologically parameters which are not dependent on any intermediate processes such as temperature, relative humidity, sunshine hour, wind speed and evaporation can be modelled by unconditional multiple linear regression assume a direct link between regional-scale predictors and local predict ands, while precipitation follows a condition process because of its regulation by intermediate process of wet day occurrence (Wilby et al., 2002). Taking consideration importance of surface air temperature it would be interesting to study the long-term variation of surface air temperature at Chhattisgarh in Raipur. In the present study efforts have been made to analyze meteorological data aspects of climate change at district Raipur in Chhattisgarh state.

\section{Materials and Methods}

\subsection{Study region}

Raipur district is a district in the Chhattisgarh state of India. Raipur is the administrative headquarters of the district. The geographical area of Raipur district is about $13,083 \mathrm{~km}^{2}$. The study area is having Latitude of $21.2376284^{\circ} \mathrm{E}$ and Longitude of $81.5962147^{\circ} \mathrm{N}$. It is located near the centre of a large plain, and referred as the "rice bowl of India". The Mahanadi River flows to the east of the city of Raipur, and the southern side has dense forests. Raipur has a tropical wet and dry climate; temperatures remain moderate throughout the year, except from March to June, which can be extremely hot. The temperature in April-May sometimes rises above $48^{\circ} \mathrm{C}\left(118^{\circ} \mathrm{F}\right)$. In summers, the temperature can also go up to $50{ }^{\circ} \mathrm{C}$. The city receives average annual precipitation of about 1,385 mm (51 in).

\subsection{Data extraction}

\subsubsection{Reanalysis data}

National Centre for Environmental Prediction (NCEP/NCAR) reanalysis dataset has been used for the monthly mean atmospheric variables were derived for the period from January 1971 to December 2003. The NCEP/NCAR reanalysis monthly means and other derived data variables are available on these 17 constant pressure levels in the horizontal and vertical resolution of 2.5 degree latitude $\times 2.5$ degree longitude global grid $(144 \times 73)$.

\subsubsection{GCM data}


The GCM selected in this study is developed by Canadian Centre for Climate Modelling and Analysis CGCM3 has resolution of $\left(3.75^{\circ}\right.$ latitude $\times 3.75^{\circ}$ longitude). The predictor variables are available for period 2001-2100 for CGCM3 model. The future scenarios considered in this study are A1B and A2 for CGCM3 model. Availability of data in SDSM compatible format and literature review are the main reason behind selection of CGCM3 model. Further, this model has been in a widespread way used in statistical downscaling of climate variables over Indian Sub-continent (Anandhi et al., 2008; Mahmood et al., 2012; Singh et al., 2015). The gridded predictor variables of NCEP/NCAR and CGCM 3 for the nearest grid in the study area have been downloaded directly from the websites (PCIC, 2004) of Data Access Integration (DAI), (NCEP, 2001) and Canadian Climate Impacts Scenarios (CCIS) respectively. The predictors are simulated under historical GHG and aerosol concentration experiment as well as Special Report on Emission Scenarios (SRES) A1B and A2 for CGCM3 model. Long term series are (2011-2040, 2041-2070 and 20712099) of observed daily maximum temperature, minimum temperature, evaporation, wind speed, relative humidity, and sunshine hour and base periods from 1971 to 2003 from (CFSR, 2014) has been used in this study.

\subsection{Statistical down-scaling model (sdsm)}

For statistical downscaling, predictands of climatic parameters and predictors (NCEP reanalyzed 26 parameters) for concurrent period were analyzed for gaps, outliers, statistics so that these series can further be used in weather generator process. The Selection of a set of appropriate predictors is an important task in downscaling process and for this proper understanding of physical process and the knowledge of physically sensible predictors that can represent atmospheric process are essential (Wilby et al., 2002; Huang et al., 2011, Jaiswal et al., 2015 etc.). Several methods were propagated by different researchers for selection of appropriate set of predictors (Benestad et al., 2007, Shongwe et al., 2006, Tripathi et al., 2006 etc.) and in the present study, percentage reduction method (Mahmood and Babel, 2014) along with scatter diagram were used for selection of an appropriate set of predictors. In percentage reduction method, the correlation coefficients between predictands (Predictand; noun (plural predictands): (mathematics) that which is to be predicted) (i.e. precipitation, used as a predictand) and predictors (26 NCEP rescaled parameters) is computed using conditional approach for annual, monthly and seasonal for monsoon months. The correlation coefficients were then arranged in descending order and top 10 predictors were selected. The predictors ranked first in this process can be termed as super predictor (SP) and using this super predictor, absolute correlation coefficient, absolute partial correlation and percentage reduction (PR) can be computed for remaining 9 predictors using following equation.

$P R=\frac{P_{r}-R}{R}$ $\ldots 1$ Where,

$\mathrm{P}_{\mathrm{r}}$ and $\mathrm{R}$ are the partial and absolute correlation coefficient respectively.

In order to avoid multi-co-linearity, all predictors having PR-value more than 0.05 and other predictors having high individual correlation with super predictor were removed from consideration. At the end, a predictor having lowest PR-value was considered the second super predictor. Similar approach is applied to get third, fourth and other predictors. In general, one to three predictors are sufficient to model climatic variability (Wilby et al., 2002, Chu et al., 2010, Mahmood and Babel, 2014). After selecting a set of appropriate predictors, empirical relations between predictand and selected predictors were developed considering appropriate transformation process (conditional for precipitation and unconditional for other climatic parameters). The monthly, seasonal or annual models can be developed in SDSM using K-fold cross validation (Markatou et al., 2005, Bedia et al., 2013, Casanueva, 2014). In K-fold cross validation, whole data series is divided in two parts and first $((\mathrm{K}-1) / \mathrm{K})$ part is taken for calibration where appropriate transformation and model types can be used to develop statistical relationships while remaining $(1 / K)$ part of series is used for validation purpose. The performance of model can be evaluated with the help of explained variance ( $R-$ squared value), root mean square error and graphical representation. If calibrated and validated results found satisfactorily, the developed model can be used to generate future series of precipitation using series of predictands for different climate scenarios. The generated data can be debised using following equations separately for precipitation and other climatic variables.

For precipitation

$\left(P_{d}\right)_{i, j}=\frac{\left(P_{\text {gen }}\right)_{i, j}-\left(\overline{P_{\text {obs }}}\right)_{i}}{\left(P_{\text {gen }}\right)_{i}}$

For other climatologically parameters

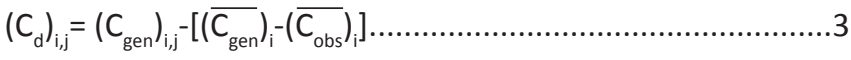
Where,

$\left(P_{d}\right)_{i, j}$ and are the debiased and generated precipitation of $j^{\text {th }}$ day of $\mathrm{i}^{\text {th }}$ month respectively and and are the observed and generated mean daily rainfall for $i^{\text {th }}$ month respectively and same as for the climatologically parameters. The computation and comparison of several statistics for observed and predicted data can be done in this software to examine the changes in projected climate. Also, the time series analysis and frequency analysis can be performed to plot time series, quantile-quantile plot, pdf plot, frequency analysis and frequency plot.

\section{Results and Discussion}

\subsection{Analysis of results}

The SDSM-DC software has been used to generate future series for climatic parameters of Chhattisgarh (Raipur) the climatic scenario under $\mathrm{A} 1 \mathrm{~B}$ and $\mathrm{A} 2$ future climate forcing conditions for three future periods namely FP-1 (2011-2040), FP-2 (2041-2070) and FP-3 (2071-2099). Twenty six NCEP reanalyzed predictors with climatic data including maximum, 
minimum temperature, relative humidity, sunshine hour, evaporation and wind speed of Chhattisgarh (Raipur). These data are analyzed using quality control option in SDSM and no gap was found in any of the series.

\subsection{Prediction of climate variables}

The different climatic variables were predicted using CGCM generated predictors of $A 1 B$ and $A 2$ climatic forcing condition for three different periods FP-1 (2011-2040), FP-2 (2041-2070) and FP-3 (2071-2099). Ten generated series were debiased and various statistics including mean, maximum, minimum, sum, peak over threshold, peak below threshold, variance, percentile etc were computed and compared with statistics of observed series of base period (1971-2003). The comparison of mean monthly values for different generated periods FP-1, FP-2 and FP-3 with observed (1971-2003) series under A1B and $A 2$ climate. The analysis of predicted changes in climatic variables is presented below.

\subsection{Maximum temperature}

From the analysis of generated series of maximum temperature from A1B scenario, it has been observed that mean monthly maximum temperature may rise during February to April, May to June, and July to November in all three periods. Under A2 climatic condition, the mean monthly maximum temperature may increase in all the months except January, November and December during FP-1 period (2011-2040), January to November during FP-2 period (2041-2070) and during FP-3 period (2071-2099) January to November. The average number of days with maximum temperature more than $40^{\circ} \mathrm{C}$ may increase in the months of April and to May, while June month may experience less number of hot days which implies more intense heat wave in summer season under both the scenarios. Figure 1 represents the above statement.

Mean maxtemp obser_1971_2003 $\square$ Mean maxtemp gen_2011_2040

Mean maxtemp gen_2041_2070

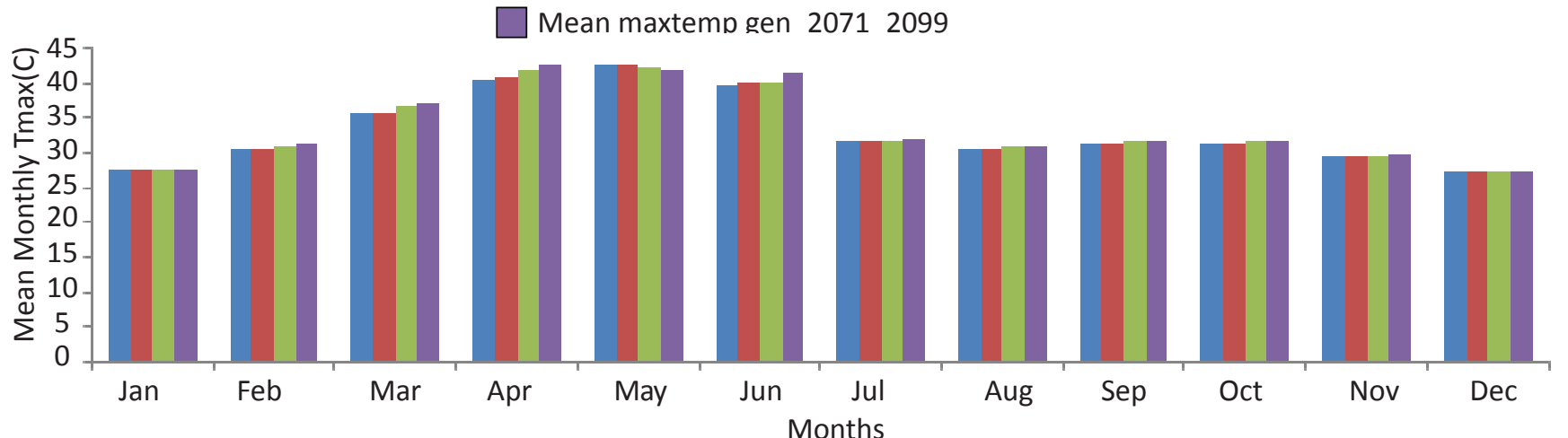

Figure 1: Compression of A1B scenario for observed and generated mean monthly Tmax

\subsubsection{Maximum temperature of peak over threshold value}

From the analysis of generated series of maximum temperature of peak over threshold from A1B scenario, it has been observed that monthly maximum temperature of peak over threshold may rise during January to March, April to June and July to November in all three periods, given in Figue 1. Under A2 climatic condition, monthly maximum temperature of peak over threshold may increase in March to June all the all the periods. The average number of days with maximum temperature of peak over threshold more than $40{ }^{\circ} \mathrm{C}$ may increase in the months of March, April and June. While, May month may experience less number of hot days this implies more intense heat wave in summer season under both the scenarios. The more graphical representation has also been done for remaining parameters vz; relative humidity, evaporation, sunshine hours and wind speed etc.

\subsection{Minimum temperature}

The mean monthly minimum temperature under $\mathrm{A} 1 \mathrm{~B}$ climate forcing condition may increase by $0.18 \%$ to $6.36 \%$ during summer months (February to May) in all three future predictive periods while decrease by $0.5 \%$ to $12.82 \%$ in remaining months (June to December), given in Figure 2.
The minimum temperature series for future periods under $\mathrm{A} 2$ condition confirmed an increase of minimum temperature in the range of $0.39 \%$ to $9.17 \%$ in most of the months except June to October where there may be slight decreased in minimum temperature. The increased minimum temperature during summer and winter months may increase user demands and water requirements of crops in Rabi season. The number of cold days below $10{ }^{\circ} \mathrm{C}$ will be increased significantly in July \& December while decrease slightly in June to October in all three future periods under both the scenarios.

\subsubsection{Minimum temperature of peak below threshold value}

From the analysis of generated series of minimum temperature of peak blow threshold from A1B scenario, it has been observed that monthly minimum temperature of peak below threshold may rise during January, February and October and in all three periods. Under A2 climatic condition, monthly maximum temperature of peak below threshold may increase in January, February and October all the all the periods. The average number of days with minimum temperature of peak below threshold more than $10{ }^{\circ} \mathrm{C}$ may increase in the months of January. While, October, November and December month may experience less number of hot days which implies 
Mean Tmin obser_1971_2003 $\square$ Mean Tmin gen_2011_2040 $\square$ Mean Tmin gen_2041_2070

Mean Tmin gen_2071_2099

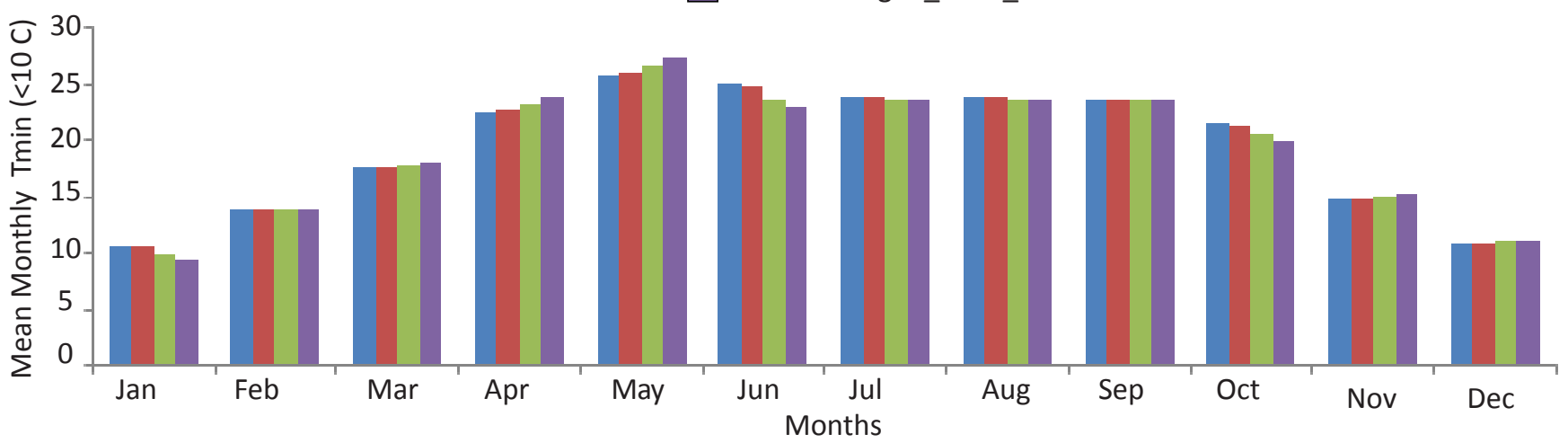

Figure 2: Compression of A1B scenario for observed and generated mean monthly Tmin

more intense heat wave in summer season under both the scenarios.

\subsection{Relative humidity}

The analysis of generated multiple series using CGCM A1B predictors data indicated that the mean monthly relative humidity may increase in the month of February, May to August and December. While decrease in the remaining months in all three period under investigation. The future projection of relative humidity under A2 climatic condition revealed that the humidity may increase in almost all the months except February, April, and June to December where there may be slight decrease in humidity. The relative humidity will increase significantly in the month of May and June (1.39\% to $39 \%)$ indicative of early monsoon activities in the region under both the scenarios. The decreasing humidity in March to January may require more irrigation water for crops in the region.

\subsubsection{Relative humidity of peak over threshold value}

The analysis of generated multiple series using CGCM A1B predictors data indicated that the mean monthly relative humidity of peak over threshold value may increase in the month of January to August. While decrease in the remaining months in all three period under investigation. The future projection of relative humidity under A2 climatic condition revealed that the humidity may increase in almost all the months except February and April, June to December where there may be slight decrease in humidity. The relative humidity will increase significantly in the month of June to August (1.19\% to $24.45 \%)$ indicative of early monsoon activities in the region under both the scenarios. The decreasing humidity in March to January may require more irrigation water for crops

Table 1: Compression of A1B scenario for observed and generated POT relative humidity

\begin{tabular}{|c|c|c|c|c|c|c|c|}
\hline \multicolumn{8}{|c|}{ For A1B RH Scenario } \\
\hline \multirow[t]{2}{*}{ Month } & \multicolumn{7}{|c|}{ Pot Year ${ }^{-1}$} \\
\hline & $\begin{array}{c}\text { Obser_1971_ } \\
2003\end{array}$ & $\begin{array}{c}\text { Gen_2011_- } \\
2040\end{array}$ & $\begin{array}{c}\text { Gen_2041_- } \\
2070\end{array}$ & Gen_2071_2099 & FP-1 & FP-2 & FP-3 \\
\hline January & 0.01 & 0 & 0.016667 & 0.036667 & 0 & 40 & 72.7272727 \\
\hline February & 0.006667 & 0.006667 & 0.023333 & 0.003333 & 0 & 71.4285714 & -100 \\
\hline March & 0 & 0 & 0 & 0 & 0 & 0 & 0 \\
\hline April & 0 & 0 & 0 & 0 & 0 & 0 & 0 \\
\hline May & 0 & 0 & 0 & 0.543333 & 0 & 0 & 100 \\
\hline June & 1.143333 & 1.356667 & 7.62 & 10.50667 & 15.72 & 85.00 & 89.12 \\
\hline July & 9.836667 & 10.85 & 16.68333 & 21.22 & 9.34 & 41.04 & 53.64 \\
\hline August & 13.88 & 15.14 & 22.11 & 25.46333 & 8.32 & 37.22 & 45.49 \\
\hline September & 8.673333 & 8.113333 & 9.786667 & 9.31 & -6.90 & 11.38 & 6.84 \\
\hline October & 1.533333 & 1.243333 & 1.096667 & 0.42 & -23.32 & -39.82 & -265.08 \\
\hline November & 0.46 & 0.4 & 0.026667 & 0.073333 & -15.00 & -1625.00 & -527.27 \\
\hline December & 0 & 0 & 0 & 0 & 0 & 0 & 0 \\
\hline
\end{tabular}


in the region. Table 1 is the tabular form of given statement;

\subsubsection{Relative humidity of peak below threshold value}

The analysis of generated multiple series using CGCM A1B predictors data indicated that the mean monthly relative humidity of peak below threshold value may increase in the month of March. While decrease in the remaining months in all three period under investigation. The future projection of relative humidity under $\mathrm{A} 2$ climatic condition revealed that the humidity may decrease in almost all the months. Table 2 is given as in tabular form;

Table 2: Compression of A1B scenario for observed and generated PBT relative humidity

\begin{tabular}{|c|c|c|c|c|c|c|c|}
\hline \multicolumn{8}{|c|}{ For A1B RH Scenario } \\
\hline \multirow[t]{2}{*}{ Month } & \multicolumn{7}{|c|}{ Pot Year ${ }^{-1}$} \\
\hline & $\begin{array}{c}\text { Obser_1971_ } \\
2003\end{array}$ & $\begin{array}{c}\text { Gen_2011_- } \\
2040\end{array}$ & $\begin{array}{c}\text { Gen_2041_- } \\
2070\end{array}$ & Gen_2071_2099 & FP-1 & FP-2 & FP-3 \\
\hline January & 0 & 0 & 0 & 0 & 0 & 0 & 0 \\
\hline February & 0 & 0 & 0 & 0 & 0 & 0 & 0 \\
\hline March & 1.41 & 1.49 & 2.313333 & 3.033333 & 5.37 & 39.05 & 53.52 \\
\hline April & 24.08 & 20.75333 & 17.06667 & 12.84667 & -16.03 & -41.09 & -87.44 \\
\hline May & 29.16 & 24.20333 & 15.95 & 10.13333 & -20.48 & -82.82 & -187.76 \\
\hline June & 4.616667 & 2.99 & 0.4 & 0.37 & -54.40 & -1054.17 & -1147.75 \\
\hline July & 0 & 0 & 0 & 0 & 0 & 0 & 0 \\
\hline August & 0 & 0 & 0 & 0 & 0 & 0 & 0 \\
\hline September & 0 & 0 & 0 & 0 & 0 & 0 & 0 \\
\hline October & 0 & 0 & 0 & 0 & 0 & 0 & 0 \\
\hline November & 0 & 0 & 0 & 0 & 0 & 0 & 0 \\
\hline December & 0 & 0 & 0 & 0 & 0 & 0 & 0 \\
\hline
\end{tabular}

\subsection{Sunshine hour}

The sunshine hour projection for future periods under $\mathrm{A} 1 \mathrm{~B}$ an increase of $1 \%$ to $6.5 \%$ in the month of April indicative and
A2 scenarios confirmed of intense heat wave in January to December in summer season, while other months may have lesser periods of sunshine hours. Table 3 is the tabular form

Table 3: Compression of A1B scenario for observed and generated POT sunshine hour

\begin{tabular}{|c|c|c|c|c|c|c|c|}
\hline \multicolumn{8}{|c|}{ For A1B Sunshine Scenario } \\
\hline \multirow[t]{2}{*}{ Month } & \multicolumn{7}{|c|}{ Pot Year ${ }^{-1}$} \\
\hline & $\begin{array}{c}\text { Obser_1971_- } \\
2003\end{array}$ & $\begin{array}{c}\text { Gen_2011_- } \\
2040\end{array}$ & $\begin{array}{c}\text { Gen_2041_- } \\
2070\end{array}$ & $\begin{array}{c}\text { Gen_2071_ } \\
2099\end{array}$ & FP-1 & FP-2 & FP-3 \\
\hline January & 0 & 0.003333 & 0.025 & 0.033333 & 100 & 100 & 100 \\
\hline February & 1.383333 & 0.966667 & 0.8 & 0.8375 & -43.10 & -72.92 & -65.17 \\
\hline March & 17.79583 & 11.59667 & 8.291667 & 5.108333 & -53.46 & -114.62 & -248.37 \\
\hline April & 13.56667 & 9.92 & 13.58333 & 17.9375 & -36.76 & 0.12 & 24.37 \\
\hline May & 1.1375 & 0.39 & 0.079167 & 0 & -191.67 & -1336.84 & \#DIV/0! \\
\hline June & 0.0125 & 0 & 0 & 0 & \#DIV/0! & \#DIV/0! & \#DIV/0! \\
\hline July & 4.916667 & 3.04 & 1.154167 & 0.333333 & -61.73 & -325.99 & -1375.00 \\
\hline August & 13.97917 & 8.68 & 3.391667 & 0.629167 & -61.05 & -312.16 & -2121.85 \\
\hline September & 23.53333 & 14.45333 & 7.425 & 3.6 & -62.82 & -216.95 & -553.70 \\
\hline October & 0.266667 & 0.14 & 0.054167 & 0 & -90.4762 & -392.308 & \#DIV/0! \\
\hline November & 0.104167 & 0.033333 & 0.008333 & 0.0125 & -212.5 & -1150 & -733.333 \\
\hline December & 0 & 0.003333 & 0 & 0.0125 & 100 & \#DIV/0! & 100 \\
\hline
\end{tabular}


of given statement;

\subsubsection{Sunshine hour peak over threshold value}

The sunshine hour projection for future periods under A1B and increase of $75 \%$ to $100 \%$ in the month of January and December and indicative in all months and A2 scenarios confirmed of intense heat wave in January to December in summer season, while other months may have lesser periods of sunshine hours.

\subsubsection{Sunshine hour peak below threshold value}

The sunshine hour projection for future periods under A1B and increase of $18 \%$ to $100 \%$ in the month of April, May to December and except the all months are indicative and A2 scenarios confirmed of intense heat wave in May to December in summer season, while other months may have lesser periods of sunshine hours. Table 4 is the tabular form of given statement;

Table 4: Compression of A1B scenario for observed and generated PBT sunshine hour

\begin{tabular}{|c|c|c|c|c|c|c|c|}
\hline \multicolumn{8}{|c|}{ For A1B Sunshine Scenario } \\
\hline \multirow[t]{2}{*}{ Month } & \multicolumn{7}{|c|}{ Pot Year $^{-1}$} \\
\hline & $\begin{array}{c}\text { Obser_1971_ } \\
2003\end{array}$ & $\begin{array}{c}\text { Gen_2011_- } \\
2040\end{array}$ & $\begin{array}{c}\text { Gen_2041_- } \\
2070\end{array}$ & $\begin{array}{c}\text { Gen_2071_- } \\
2099\end{array}$ & FP-1 & FP-2 & FP-3 \\
\hline January & 1.791667 & 1.33 & 1.75 & 1.291667 & -34.71 & -2.38 & -38.71 \\
\hline February & 0 & 0 & 0 & 0 & \#DIV/0! & \#DIV/0! & \#DIV/0! \\
\hline March & 0 & 0 & 0 & 0 & \#DIV/0! & \#DIV/0! & \#DIV/0! \\
\hline April & 0.004167 & 0.006667 & 0.004167 & 0.004167 & 37.50 & 0.00 & 0.00 \\
\hline May & 0.266667 & 0.396667 & 1.929167 & 3.9 & 32.77 & 86.18 & 93.16 \\
\hline June & 16.575 & 13.80667 & 24.60417 & 29.0625 & -20.05 & 32.63 & 42.97 \\
\hline July & 0 & 0.006667 & 0.1625 & 1.116667 & 100.00 & 100.00 & 100.00 \\
\hline August & 0.004167 & 0.013333 & 0.495833 & 2.129167 & 68.75 & 99.16 & 99.80 \\
\hline September & 0.054167 & 0.086667 & 1.9125 & 4.654167 & 37.50 & 97.17 & 98.84 \\
\hline October & 1.566667 & 1.396667 & 6.795833 & 10.02917 & -12.17 & 76.95 & 84.38 \\
\hline November & 8.466667 & 7.043333 & 12.72917 & 14.49167 & -20.21 & 33.49 & 41.58 \\
\hline December & 10.68333 & 8.406667 & 13.16667 & 12.8375 & -27.08 & 18.86 & 16.78 \\
\hline
\end{tabular}

\subsection{Evaporation}

Under A1B scenario, there will be significant increase of evaporation in the range of $6.7 \%$ to $43 \%$ from base period evaporation in the months of January to April and July to September in all three future assessment periods. All other months indicates negative trend with significant reduction may occur during May and June. The evaporation trend for three future periods were investigated under A2 scenario and found that there will be significant increase of mean monthly evaporation in the range of $4 \%$ to $45 \%$ in January to April and July to September. The other months may indicate decrease of evaporation with significant downward trend in May and June ( $13 \%$ to $36.5 \%$ ). Table 5 is the tabular form of given statement;

\subsubsection{Evaporation of peak over threshold value}

\subsubsection{Evaporation of peak below threshold value}

Under A1B scenario, there will be significant increase of evaporation in the range of $6.7 \%$ to $43 \%$ from base period evaporation in the months of January to April \& July to September in all three future assessment periods. All other months indicates negative trend with significant reduction may occur during May and June. The evaporation trend for three future periods were investigated under A2 scenario and found that there will be significant increase of mean monthly evaporation in the range of $4 \%$ to $45 \%$ in January to April and July to September. The other months may indicate decrease of evaporation with significant downward trend in May \& June ( $13 \%$ to $36.5 \%)$. Table 6 is given as in tabular form;

\subsection{Wind speed}

\subsubsection{Wind speed of peak over threshold value}

Under A1B scenario, there will be significant increase of wind speed in the range of $6.7 \%$ to $45 \%$ from base period evaporation in the months of January to April \& July to September in all three future assessment periods. All other months indicates negative trend with significant reduction may occur during May and June. The evaporation trend for three future periods were investigated under A2 scenario and found that there will be significant increase of mean monthly evaporation in the range of $8 \%$ to $45 \%$ in January to April and July to September. The other months may indicate decrease of 


\begin{tabular}{|c|c|c|c|c|c|c|c|}
\hline \multicolumn{8}{|c|}{ For A1B EVAPO Scenario } \\
\hline \multirow[t]{2}{*}{ Month } & \multicolumn{7}{|c|}{ Pot Year ${ }^{-1}$} \\
\hline & $\begin{array}{c}\text { Obser_1971_ } \\
2003\end{array}$ & $\begin{array}{c}\text { Gen_2011_ } \\
2040\end{array}$ & $\begin{array}{c}\text { Gen_2041_ } \\
2070\end{array}$ & $\begin{array}{c}\text { Gen_2071_ } \\
2099\end{array}$ & FP-1 & FP-2 & FP-3 \\
\hline January & 0 & 0 & 0 & 0 & \#DIV/0! & \#DIV/0! & \#DIV/0! \\
\hline February & 0 & 0 & 0 & 0 & \#DIV/0! & \#DIV/0! & \#DIV/0! \\
\hline March & 2.584615 & 2.6 & 4.246154 & 5.123077 & 0.591716 & 39.13043 & 49.54955 \\
\hline April & 20.6 & 19.46538 & 21.62692 & 22.04615 & -5.82889 & 4.748355 & 6.559665 \\
\hline May & 23.39231 & 20.25385 & 17.00385 & 13.26923 & -15.4956 & -37.5707 & -76.2899 \\
\hline June & 12.28846 & 9.880769 & 5.919231 & 5.934615 & -24.3675 & -107.602 & -107.064 \\
\hline July & 0.361538 & 0.346154 & 0.053846 & 0.157692 & -4.44444 & -571.429 & -129.268 \\
\hline August & 0 & 0 & 0 & 0 & \#DIV/0! & \#DIV/0! & \#DIV/0! \\
\hline September & 0 & 0 & 0 & 0 & \#DIV/0! & \#DIV/O! & \#DIV/0! \\
\hline October & 0 & 0 & 0 & 0 & \#DIV/0! & \#DIV/0! & \#DIV/0! \\
\hline November & 0 & 0 & 0 & 0 & \#DIV/0! & \#DIV/0! & \#DIV/O! \\
\hline December & 0 & 0 & 0 & 0 & \#DIV/0! & \#DIV/0! & \#DIV/0! \\
\hline
\end{tabular}

Table 6: Compression of A1B scenario for observed and generated PBT evaporation

\begin{tabular}{|c|c|c|c|c|c|c|c|}
\hline \multicolumn{8}{|c|}{ For A1B EVAPO Scenario } \\
\hline \multirow[t]{2}{*}{ Month } & \multicolumn{7}{|c|}{ Pot Year ${ }^{-1}$} \\
\hline & $\begin{array}{c}\text { Obser_1971_ } \\
2003\end{array}$ & $\begin{array}{c}\text { Gen_2011_- } \\
2040\end{array}$ & $\begin{array}{c}\text { Gen_2041_- } \\
2070\end{array}$ & $\begin{array}{c}\text { Gen_2071_- } \\
2099\end{array}$ & FP-1 & FP-2 & FP-3 \\
\hline January & 34.71923 & 31.53462 & 31.41538 & 30.66538 & -10.0988 & -10.5167 & -13.2196 \\
\hline February & 12.61154 & 11.34231 & 10.47308 & 10.06538 & -11.1902 & -20.4187 & -25.2961 \\
\hline March & 1.684615 & 1.234615 & 0.723077 & 0.384615 & -36.4486 & -132.979 & -338 \\
\hline April & 0.084615 & 0.069231 & 0.05 & 0.061538 & -22.2222 & -69.2308 & -37.5 \\
\hline May & 1.269231 & 1.626923 & 2.946154 & 3.830769 & 21.98582 & 56.91906 & 66.86747 \\
\hline June & 4.880769 & 5.219231 & 7.55 & 7.042308 & 6.484893 & 35.35405 & 30.69361 \\
\hline July & 8.411538 & 7.573077 & 8.657692 & 7.919231 & -11.0716 & 2.843181 & -6.21661 \\
\hline August & 11.61538 & 10.26923 & 8.480769 & 6.084615 & -13.1086 & -36.9615 & -90.8976 \\
\hline September & 21.50385 & 19.22308 & 17.76538 & 16.14615 & -11.8647 & -21.0435 & -33.1825 \\
\hline October & 28.59231 & 26.21923 & 27.47692 & 26.86923 & -9.0509 & -4.05935 & -6.41283 \\
\hline November & 34.16923 & 30.84615 & 30.63846 & 29.66538 & -10.7731 & -11.524 & -15.1822 \\
\hline December & 38.95385 & 35.45385 & 35.43462 & 34.31538 & -9.87199 & -9.93162 & -13.5171 \\
\hline
\end{tabular}

evaporation with significant downward trend in May \& June ( $18 \%$ to $39.5 \%)$. Table 7 is the tabular form of given statement;

\subsubsection{Wind speed of peak below threshold value}

Under A1B scenario, there will be significant increase of wind speed in the range of $9.7 \%$ to $43 \%$ from base period evaporation in the months of January to April and July to September in all three future assessment periods. All other months indicates negative trend with significant reduction may occur during May and June. The evaporation trend for three future periods were investigated under A2 scenario and found that there will be significant increase of mean monthly evaporation in the range of $14 \%$ to $45 \%$ in January to April and July to September. The other months may indicate decrease of evaporation with significant downward trend in May \& June ( $18 \%$ to $38.5 \%$ ). Table 8 is the tabular form of given statement; 


\begin{tabular}{|c|c|c|c|c|c|c|c|}
\hline \multicolumn{8}{|c|}{ For A1B Scenario } \\
\hline \multirow[t]{2}{*}{ Month } & \multicolumn{7}{|c|}{ Pot Year ${ }^{-1}$} \\
\hline & $\begin{array}{c}\text { Obser_1971_ } \\
2003\end{array}$ & $\begin{array}{c}\text { Gen_2011_- } \\
2040\end{array}$ & $\begin{array}{c}\text { Gen_2041_- } \\
2070\end{array}$ & $\begin{array}{c}\text { Gen_2071_- } \\
2099\end{array}$ & FP-1 & FP-2 & FP-3 \\
\hline January & 0 & 0 & 0 & 0 & \#DIV/0! & \#DIV/0! & \#DIV/0! \\
\hline February & 0.00303 & 0 & 0 & 0 & \#DIV/0! & \#DIV/0! & \#DIV/0! \\
\hline March & 0.984848 & 0.669697 & 0.209091 & 0.036364 & -47.0588 & -371.014 & -2608.33 \\
\hline April & 0.945455 & 1.09697 & 2.454545 & 4.693939 & 13.81215 & 61.48148 & 79.85797 \\
\hline May & 16.68485 & 17.00909 & 23.18182 & 25.20909 & 1.906289 & 28.02614 & 33.81416 \\
\hline June & 8.460606 & 6.472727 & 1.566667 & 1.451515 & -30.7116 & -440.039 & -482.881 \\
\hline July & 1.990909 & 1.766667 & 0.454545 & 0.348485 & -12.693 & -338 & -471.304 \\
\hline August & 0 & 0 & 0 & 0 & \#DIV/0! & \#DIV/0! & \#DIV/0! \\
\hline September & 0.733333 & 0.457576 & 0.160606 & 0.063636 & -60.2649 & -356.604 & -1052.38 \\
\hline October & 0 & 0 & 0 & 0 & \#DIV/0! & \#DIV/0! & \#DIV/0! \\
\hline November & 0 & 0 & 0 & 0 & \#DIV/0! & \#DIV/0! & \#DIV/0! \\
\hline December & 0 & 0 & 0 & 0 & \#DIV/0! & \#DIV/0! & \#DIV/0! \\
\hline \multirow{2}{*}{\multicolumn{8}{|c|}{$\begin{array}{c}\text { Table 8: Compression of A1B scenario for observed and generated PBT wind sp } \\
\text { For A1B Scenario }\end{array}$}} \\
\hline & & & & & & & \\
\hline \multirow[t]{2}{*}{ Month } & \multicolumn{7}{|c|}{ Pot Year ${ }^{-1}$} \\
\hline & $\begin{array}{c}\text { Obser_1971_- } \\
2003\end{array}$ & $\begin{array}{c}\text { Gen_2011_- } \\
2040\end{array}$ & $\begin{array}{c}\text { Gen_2041_- } \\
2070\end{array}$ & $\begin{array}{c}\text { Gen_2071_- } \\
2099\end{array}$ & FP-1 & FP-2 & FP-3 \\
\hline January & 0.339394 & 0.19697 & 0.381818 & 0.824242 & -72.3077 & 11.11111 & 58.82353 \\
\hline February & 0.021212 & 0.021212 & 0.048485 & 0.042424 & 0 & 56.25 & 50 \\
\hline March & 0.00303 & 0.012121 & 0.006061 & 0.015152 & 75 & 50 & 80 \\
\hline April & 0 & 0 & 0 & 0 & \#DIV/0! & \#DIV/0! & \#DIV/0! \\
\hline May & 0.109091 & 0.033333 & 0 & 0 & -227.273 & \#DIV/0! & \#DIV/0! \\
\hline June & 0 & 0.012121 & 0.115152 & 0.469697 & 100 & 100 & 100 \\
\hline July & 0.030303 & 0.057576 & 0.218182 & 0.539394 & 47.36842 & 86.11111 & 94.38202 \\
\hline August & 31 & 28.18182 & 28.17576 & 27.24242 & -10 & -10.0237 & -13.7931 \\
\hline September & 2.257576 & 2.681818 & 6.315152 & 8.927273 & 15.81921 & 64.25144 & 74.71147 \\
\hline October & 7.330303 & 6.436364 & 5.115152 & 4.072727 & -13.8889 & -43.3057 & -79.9851 \\
\hline November & 1.393939 & 0.951515 & 0.381818 & 0.484848 & -46.4968 & -265.079 & -187.5 \\
\hline December & 0.390909 & 0.448485 & 0.684848 & 0.930303 & 12.83784 & 42.92035 & 57.98046 \\
\hline
\end{tabular}

\section{Conclusion}

The prediction of maximum and minimum temperature concluded a significant increase of temperature in summer months. The future scenario may demand more water to meet user demands and crop water requirement in the region. The more sunshine hours and higher evaporation due to climate change resulting change in more intense heat waves and require more water in different sectors of life, industries and agriculture. The monsoon months may experience higher relative humidity in the future under both climatic conditions resulting required enhance moisture level from the trend analysis under both $\mathrm{A} 1 \mathrm{~B}$ and $\mathrm{A} 2$ climate forcing conditions. Looking in to changing climatic condition, it is necessary to modify policy and develop adaptation strategy for water resource management, agriculture, health and many more areas of life.

\section{References}

Anandhi, A., Srinivas, V.V., Nanjundiah, R., Kumar, N., 2008. Downscaling precipitation to River basin in India for 
IPCC SRES scenarios using support vector machine. International Journal of Climatology 28, 401-420.

Bedia J., Herrera S., San-Martin D., Koutsias N., Gutierrez, J.M., 2013. Robust projections of fire weather index in the mediterranean using statistical downscaling. Climate Change 120, 229-247.

Benestad, R.E., Hanssen-Bauer, I., Forland, E.J., 2007. An evaluation of statistical models for downscaling precipitation and their ability to capture long-term trends. International Journal of Climatology 27(5), 649-655.

Casanueva, A., Frias, M. D., Herrera, S., San-Martin, D., Kaminovic, K., Gutierrez, J.M., 2014. Statistical downscaling of climate impact indices: Testing the direct approach. Climate Change 127, 547-560.

Chu, J.T., Xia, J., Xu, C.Y., Singh, V.P., 2010. Statistical downscaling of daily mean temperature, pan evaporation and precipitation for climate change scenarios in Haihe River, China. Theoretical and Applied Climatology 99, 149-161.

CFSR, 2014. The National Centers for Environmental Prediction (NCEP) was completed over the 36-year period of 1979 through 2014. Available from: http://globalweather. tamu.edu/. www.globalweather.tamu.edu. Accessed in August, 2018.

Fowler, H.J., Blenkinsop, S., Tebaldi, C., 2007. Linking climate change modelling to impacts studies: Recent advances in downscaling techniques for hydrological modelling, International Journal of Climatology 27(12), 1547-1578.

Ghosh, S., Mishra, C., 2010. Assessing hydrological impacts of climate change: Modeling techniques and challenges, The Open Hydrology Journal 4, 115-121.

Huang, J., Zhang, J., Zhang, Z., Xu, C., Wang, B., Yao, J., 2011. Estimation of future precipitation change in the Yangtze River basin using statistical downscaling method. Stochastic Environmental Research and Risk Assessment 25, 781-792.

Intergovernmental Panel on Climate Change (IPCC), 2007. Summary for policymakers, of climate change 2007 impacts, adaptation and vulnerability, (Ed.) By Parry, M.L., Canziani, O.F., Palutikof, J.P., van der Linden, P.J., Hanson, C.E., Contribution of working group II to the fourth assessment report of the Intergovernmental Panel on Climate Change: Cambridge, United Kingdom, Cambridge University Press.

Jaiswal, R.K., Tiwari, H.L., 2015. Downscaling and generation of future scenarios for maximum temperature in Upper Mahanadi basin, International Journal of Frontier Technology 2(2), 41-46.

Mahmood, R., Babel, M.S., 2012. Evaluation of SDSM developed by annual and monthly sub-models for downscaling temperature and precipitation in the Jhelum basin, Pakistan and India. Theoretical and Applied Climatology 113, 27-44.

Mahmood, R., Babel, M.S., 2014. Future changes in extreme temperature events using the statistical downscaling model (SDSM) in the trans-boundary region of the Jhelum River basin. Weather and Climate Extremes 5(6), 56-66.

Maraun, D., Wetterhall, F., Ireson, A.M., Chandler, R.E., Kendon, E.J., Widmann, M., Brienen, S., Rust, H.W., Sauter, T., THembl, M., Venema, V.K.C., Chun, K.P., Goodes, C.M., Jones, R.G., Onof, C., Vrac, M., Tisseuil, C., Vrac, M., Lek, S., Wade, A.J., 2010. Statistical downscaling of river flow. Journal of Hydrology 385(1), 279-291.

Markatou, M., Tian, H., Biswas, S., Hripcsak, G., 2005. Analysis of variance of cross-validation estimators of the generalization error. The Journal of Machine Learning Research 6, 1127-1168.

NCEP, 2001. HadCM3 predictors: A2(a) and B2(a) experiments. Available from http://loki.qc.ec.gc.ca/DAl/predictors-e. html. www.climate-scenarios.canada.ca. Accessed in August, 2018.

PCIC, 2004. Canadian climate impacts and scenarios project, canada. In 2004, provision of national scenarios moved to Environment Canada. Available from: http://www. cics.uvic.ca/scenarios/index.cgi. www.pacificclimate. org. Accessed in August, 2018.

Shongwe, E.M., Landman, W.A., Mason, S.J., 2006. Performance of recalibration systems for GCM forecasts for Southern Africa. International Journal of Climatology 26, 1567-1585.

Singh, D., Jain, S.K., Gupta, R.D., 2015. Statistical downscaling and projection of future temperature and precipitation change in middle catchment of Sutlej River basin, India. Journal of Earth System Science 124, 843-860.

Tripathi, S., Srinivas, V.V., Nanjundiah, R.S., 2006. Downscaling precipitation for climate change scenarios: A support vector machine approach. Journal of Hydrology 330(4), 621-640.

Wilby, L., Dawson, C.W., Barrow, E.M., 2002. SDSM-A decision support tool for the assessment of regional climate change and it's impacts. Environmental Model Software 17(2), 145-157.

Wilby, R. L., Dawson, C.W., Murphy, C., O' Connor, P., Hawkins, E., 2014. The Statistical Downscaling Model - Decision Centric (SDSM-DC): Conceptual basis and applications. Climate Research 61, 251-268.

Wilby, R.L., Dettinger, M.D., 2000. Streamflow changes in the Sierra Nevada, CA simulated using a statistically downscaled General Circulation Model scenario of climate change. In: McLaren, S.J., Kniveton, D.R. (Eds.), Linking Climate Change to Land Surface Change, Kluwer Academic Publishers, Netherlands, 99-121.

Wilby, R.L., Dawson, C.W., 2004. Using SDSM Version 3.1-A decision support tool for the assessment of regional climate change impacts. User Manual, United Nations framework convention on climate change, Bonn, Germany. 